\title{
COVID 19 \& Mucormycosis- The Mystery of Intertwined Pathologies
}

\author{
Pallavi Lande-Marghade
}

An anesthesiologist has been constantly pushed from the domains of being a perioperative physician to that of a COVID physician in the current COVID -19 pandemic. We have been sailing uncharted water pressured to unearth the mysteries of COVID 19 for 18 months now without any definitive treatment. Come April 2021, mucormycosis had become the talk of the town! India saw an exponential rise in cases of post covid mucormycosis. Ample theories and speculations were dug out to understand if there is a causal relationship at all. The fact is mucormycosis cases did exist in the pre-covid era as well but what led to its sudden skyrocketing numbers in covid times needed some brainstorming and hence prompted me to pen this piece of write up.

Dr Poonam Ghodki, Professor of Anaesthesiology in SKNMC \& $\mathrm{GH}$, Pune has kindly shared some brilliant inputs from her experience of managing these challenging cases on various platforms through Anaesthesiatv. She quotes that the commonly used term black fungus is a misnomer as the black fungus is a yeast with abundant melanin on the surface. Mucormycosis is a different fungal pathology that gets its characteristic appearance due to the devitalisation of affected tissues. Although ubiquitous, human beings are resistant to its deadly invasion. Under favourable circumstances, the opportunistic fungus after angioinvasion causes ischaemia and necrosis of contagious tissue forming the hallmark blackish eschar [1]. The five main types of mucormycosis described are rhino-orbitocerebral, pulmonary, cutaneous, gastrointestinal and disseminated, of which rhino-orbitocerebral has been observed to be the commonest. In the rhinoorbitocerebral variant, the fungus invades the lamina papyracea of ethmoidal sinuses and gains access to orbit leading to proptosis and blindness. It could gain entry through the cribriform plate to the brain and cause sagittal sinus thrombosis and stroke.

Gaining further clarity on managing Covid 19 cases recovery increased manifold. We encountered long term effects like benign post-covid syndrome and more dreaded long term complications such as fibrosis of lungs and bacterial and fungal opportunistic infections. Of the many fungal infections, the focus shifted mainly to Covid associated Mucormycosis (CAM) since it had definitive surgical management as an approach.
The mystery still lingers on to an ever-intriguing question does Covid 19 trigger mucormycosis? Many predisposing factors were present during Covid 19 cases as:

1. Immunosuppression: altered immune system, ciliary dysfunction, cytokine storm, thrombo-inflammatory response leading to exhaustion of immune system.

2. Administration of steroids- methylprednisolone (Recovery trial)

3. Anti-cytokine therapies- Monoclonal antibodies therapy eg. tocilizumab, itolizumab

4. Neutropenia- neutrophils protect the cells from hyphae invasion.

All the above-mentioned conditions did exist in the pre-covid era as well when antiretroviral drugs were administered. Then what could have led to the resurgence of cases during the covid pandemic particularly in the Indian subcontinent? Many ENT surgeons countrywide speculated that airborne mode of transmission is common for both covid and pulmonary mucormycosis. However, a potentially devastating rhinocerebral variant was rampant in most of the patients.

It was observed that the immunocompromised patient's mucormycosis had a predilection for nasal epithelial cells than the pulmonary alveolar cells [2]. Diabetes is an independent risk factor for Mucormycosis. Free iron overload was commonly seen in Diabetic ketoacidosis and iron being food for mucor explains the causal association between Covid 19, free iron overload in diabetic patients and occurrence of rhinocerebral mucormycosis [3]. Biomarkers like Serum Ferritin which has been found in exceptionally high levels is not an innocent bystander. Iron homeostasis is erratic with very high levels of free serum iron. Furthermore, in acidosis, the ketones break the Fe- transferrin bonds which aggravate the preexisting condition. Hypoxia catalyses the germination of spores providing the perfect conditions for the fungus to proliferate. Ironically administration of iron chelators like desferrioxamine leads to the formation of siderophore which does more harm than doing any good. Some other factors which may be contributory are prolonged mechanical ventilation, use of industrial oxygen, excessive steam inhalation,

${ }^{1}$ Department of Anaesthesia, Basildon University Hospital NHS Foundation Trust, United Kingdom.

Address of Correspondence

Dr. Pallavi Lande-Marghade

Specialty Doctor, Basildon University Hospital NHS Foundation Trust, United

Kingdom.

E-mail: editor.jaccr@gmail.com

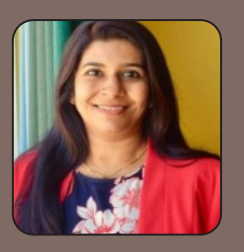

Dr Pallavi Lande-Marghade

DOI: 10.13107/jaccr.2021.v07i02.171

This is an Open Access article distributed under the terms of the Creative Commons Attribution Non-Commercial-Share Alike 4.0 License (http://creativecommons.org/licenses/by-nc-sa/4.0) which allows others to remix, tweak, and build upon the work non-commercially as long as appropriate credit is given and the new creation are licensed under the identical terms. 
excess use of zinc which also favours growth along with iron $[2,4]$.

The above-mentioned hypothesis explains the findings in the first wave of the pandemic. The second wave had more of younger sicker treated at home, without any form of invasive ventilation. It can only be speculated that the multiple variants of SARS CoV2 lead to de novo immunosuppression which may be responsible for rising cases of CAM. Common factors noted were male preponderance and indiscriminate use of steroids.

Dr Ghodki enumerated challenges associated with anaesthetic management as follows:

1. Hemodynamic instability: preexisting comorbidities, septicaemia

2. Difficult airway- disfigurement, palatal perforation

3. Amphotericin B- nephrotoxicity, hypokalaemia, arrhythmias hypotension

4. Bleeding- avascular necrosis, coagulopathy, septicaemia leading to Disseminated Intravascular Coagulation

5. Uncontrolled Blood Sugar levels- uncontrolled diabetes mandating aggressive insulin therapy
General anaesthesia remained the mainstay of the regimen [5]. Ventilatory strategies have been used to mitigate residual pulmonary effects from Covid 19. Isoflurane was used as it was found to be fungistatic. Almost all patients were either on antiplatelet or anticoagulants or both. Renoprotective measures were adopted and electrolyte imbalance was corrected [6].

These twin pathologies have thus taught a lesson to avoid indiscriminate use of steroids particularly Methylprednisolone, indiscriminate use of broad-spectrum antifungals and iron chelators. Active ENT surveillance should be employed to identify at-risk patients.

\section{Fungi are the interface organisms between life and death. - Paul Stamets.}

Conflict of interest: Nil Source of support: None

Acknowledgement: Dr Poonam Ghodki, Professor of Anaesthesia, SKNMC \& GH, Pune for her valuable inputs and throwing light on the Indian scenario of CAM.

\section{References}

1. Cornely OA, Alastruey-Izquierdo A, Arenz D, et al. Global guideline for the diagnosis and management of mucormycosis:an initiative of the European Confederation of Medical Mycology in cooperation with the Mycoses Study Group Education and Research Consortium. Lancet Infect Dis. 2019; 19:e405-21.

2. Mehta S, Pandey A (September 30, 2020) Rhino-Orbital Mucormycosis Associated With COVID-19. Cureus 12(9): 10726.

3. Afroze SN, KorleparaR, Rao GV, Madala J. Mucormycosis in a diabetic patient: A case report with an insight into its pathophysiology. Contemp Clin Dent2017; 8:662-6.
4. Group, R. C. et al. Dexamethasone in hospitalized patients with Covid19-preliminary report. N. Engl.J. Med. (2020).

5. Kulkarni PK, Reddy NB, Shrinivas B, Takkalki VV. Anesthetic considerations in the management of mucormycosis. Int J Med Public Health 2015; 5:387-90.

6. Karaaslan E. Anesthetic management of rhinoorbitocerebral mucormycosis; Focus on challenges. J Mycol Med. 2019; 29:219-222.

\section{How to Cite this Article}

Marghade-Lande P | COVID 19 \& Mucormycosis- The Mystery of Intertwined Pathologies | Journal of Anaesthesia and Critical Care Case Reports | May-August 2021; 7(2): 01-02. 